\title{
Does Age Make a Difference? Predicting Physical Activity of South Koreans
}

\author{
Britta Renner and Youlia Spivak \\ Jacobs University Bremen
}

\author{
Sunkyo Kwon \\ Hallym University
}

\author{
Ralf Schwarzer \\ Freie Universität Berlin
}

\begin{abstract}
Social cognition models of health behavior are commonly understood as being universal, which implies that they are applicable to groups varying in age or cultural background, for example. Cultural uniqueness and characteristics of life-span development, however, necessitate the study of differential effects. Accordingly, the health action process approach (HAPA) was examined in younger and middle-aged/ older adults from South Korea $(N=697)$ who participated in a longitudinal health screening study with a 6-month time lag. The HAPA model had a good fit within the middle-aged/older adult sample. Physical activity was predicted by planning, coping self-efficacy, and intention, which were, in turn, predicted by action self-efficacy, outcome expectancies, and risk perceptions. Conversely, the results indicated a poor model fit in the younger adult sample. The results suggest a different motivation for the involvement in physical activity as a function of age.
\end{abstract}

Keywords: HAPA, risk perception, self-efficacy, planning, physical activity

South Korea has experienced various and rapid economic and sociodemographic changes during the past 3 decades. Related to these changes, a dramatic shift in the leading causes of death from infectious and parasitic diseases to cardiovascular diseases and cancer occurred in the 1970s (S. Kim, Moon, \& Popkin, 2000). The transition in disease patterns from communicable to noncommunicable diseases, with cardiovascular diseases as the primary cause of death, results from lifestyle changes and an expansion of average life expectancy (M. J. Lee, Popkin, \& Kim, 2002). Physical inactivity, among other lifestyle-related factors such as poor diet, smoking, and alcohol consumption, is one of the most important risk factors for developing cardiovascular diseases, diabetes, or obesity (World Health Organization, 2003). However, as South Korea has undergone rapid economic development, the physical activities of the population, particularly job-related activities and transportation, have decreased significantly (S. K. Lee \& Sobal, 2003). Hence, recreational physical activities become increasingly important for promoting and protecting health.

Determinants of the reasons why people engage in healthpromoting behaviors are described by social-cognitive health be-

Britta Renner and Youlia Spivak, Jacobs Center for Lifelong Learning and Institutional Development, Jacobs University Bremen (formerly International University Bremen); Sunkyo Kwon, Department of Psychology, Hallym University; Ralf Schwarzer, Department of Health Psychology, Freie Universität Berlin.

This research was supported by the Deutsche Forschungsgemeinschaft Grants Re 1583/2-1 and Schw 208/11-01-03.

Correspondence concerning this article should be addressed to Britta Renner, International University Bremen, Jacobs Center for Lifelong Learning and Institutional Development, Postfach 750561, Campus Ring 1, 28759, Bremen, Germany. E-mail: b.renner@jacobs-university.de havior models. The most prominent models are the health belief model, the theory of planned behavior, and the protection motivation theory (for an overview and critique of these and other models, see Abraham \& Sheeran, 2000; Renner \& Schwarzer, 2003). The focus of these models has been on identifying a parsimonious set of predictors for forming an intention to adopt health-promoting behaviors. Predictors are constructs such as perceived barriers, social norms, disease severity, personal vulnerability, perceived self-efficacy, and so on. The current revised versions of these health behavior models share several common predictors. Outcome expectancies and perceived self-efficacy, in addition to personal vulnerability, are considered to play a major role in the intention-formation process (Bandura, 1997, 2000; Schwarzer, 1992; Weinstein, 1993). The wording of the predictors differs in these theories, but their meaning is about the same. For example, behavioral beliefs (as precursors of attitudes) can be equated to outcome expectancies, and behavioral control can be matched to perceived self-efficacy (see also Weinstein, 1993).

The health action process approach (HAPA) shares the basic concepts of most current models and extends these intentionformation models by including an additional "postintentional" phase in which intentions are translated into actions (Lippke, Ziegelmann, \& Schwarzer, 2004; Luszczynska \& Schwarzer, 2003; Renner \& Schwarzer, 2003, 2005; Schwarzer, 1992; Schwarzer et al., 2007; Schwarzer \& Renner, 2000; Sniehotta, Scholz, \& Schwarzer, 2005, 2006; Ziegelmann, Lippke, \& Schwarzer, 2006). Thus, the HAPA also incorporates basic ideas from stage models, for instance the transtheoretical model (e.g., Prochaska, Johnson, \& Lee, 1998) and the precaution adoption process model (Weinstein, 2003), and could, therefore, be considered to be a useful integration of current social-cognitive health behavior models. 
The HAPA suggests a distinction between (a) preintentional motivation processes that lead to a behavioral intention and (b) postintentional volition processes that lead to the actual health behavior. Within both phases, different patterns of social-cognitive predictors may emerge. In the preintentional motivation phase, risk perception, outcome expectancies, and action self-efficacy are seen as antecedents for intention formation. Risk perception addresses the perceived vulnerability for certain diseases. It may set the stage for a contemplation process and further elaboration of thoughts about consequences of risk behaviors and one's competence to overcome them. Outcome expectancies are seen as being mainly influential in the motivation phase, when a person balances the pros and cons of certain behavioral consequences. Further, perceived action self-efficacy, that is, the belief in one's capability to perform a desired action, is conceptualized as another determinant of intention formation.

After a person develops an inclination toward practicing a particular health behavior, the "good intention" has to be transformed into detailed instructions on how to perform the desired action within the postintentional volition processes. The terms planning and implementation intentions have been used to address this phenomenon (Armitage, 2004; Gollwitzer, 1999; Sheeran, 2002). Intentions do not induce actions directly but need to be mediated by planning, which represents a self-regulatory strategy. Coping self-efficacy contributes to the successful accomplishment of a desired action during the postintentional volition phase. In the following, the two constructs, phase-specific self-efficacy beliefs and planning, are explained in detail.

\section{Phase-Specific Self-Efficacy Beliefs}

Perceived self-efficacy has been found to be important in all stages of the health behavior change process (Bandura, 1997), but it is not always exactly the same construct. The idea is to adjust the construct to the particular situation of individuals who may be more or less advanced in the change process. The concept of phase-specific self-efficacy has been brought up by Marlatt, Baer, and Quigley (1995) in the domain of addictive behaviors and has proven useful in several domains of behavior change (cf. Marlatt et al., 1995).

The rationale for a distinction among several phase-specific self-efficacy beliefs is that during the course of health behavior change, different tasks have to be mastered, and, thus, different self-efficacy beliefs are required to master these tasks successfully. For example, a person might be confident in his or her capability to set ambitious goals and to take the initiative to become physically active (i.e., high action self-efficacy) but might not be very confident to resume physical activity after a setback. Action selfefficacy refers to the first phase of the process, in which an individual does not yet act but develops a motivation to do so. Coping self-efficacy (Schwarzer \& Renner, 2000; see also "maintenance self-efficacy," Luszczynska \& Schwarzer, 2003; Luszczynska \& Sutton, 2006), on the other hand, describes optimistic beliefs about one's capability to deal with barriers that arise during the postintentional phase. A new health behavior might turn out to be much more difficult to adhere to than expected, but a selfefficacious person responds confidently with better strategies, more effort, and prolonged persistence to overcome such hurdles. Once an action has been taken, high-coping, self-efficacious per- sons invest more effort and persist longer than those who are low in self-efficacy. When setbacks occur, they maintain the commitment to their goals.

Seen together, action self-efficacy refers to taking up an activity (preintentional motivation phase) and coping self-efficacy to maintaining the behavior (postintentional volition phase). Thus, they represent two distinct aspects of self-efficacy that follow a temporal sequence. Accordingly, the HAPA model is conceptualized as a mediator model whereby coping self-efficacy is assumed to mediate between action self-efficacy and behavior (see also Schwarzer \& Renner, 2000). Supporting this notion, studies applying the HAPA model have shown that action self-efficacy and coping self-efficacy differ in their effects on dietary behaviors (a diet low in fat and high in vitamins) and on corresponding intentions (Renner \& Schwarzer, 2005; Schwarzer \& Renner, 2000) Action self-efficacy emerged as a significant predictor of intentions, whereas coping self-efficacy contributed to the prediction of eating a low-fat and high-vitamin diet (cf., also Rodgers, Hall, Blanchard, McAuley, \& Munroe, 2002; Rodgers \& Sullivan, 2001).

\section{Planning as a Volitional Mediator for Physical Exercise}

Good intentions are more likely to be translated into action when people develop success scenarios and preparatory strategies of approaching a difficult task. Mental simulation helps to identify cues for action. The terms planning and implementation intentions have been used to address this phenomenon. Past research has already pointed to action plans. For instance, Leventhal, Singer, and Jones (1965) stated that fear appeals can facilitate health behavior change only when combined with specific instructions on when, where, and how to perform it. Renewed attention to planning emerged when the concept of implementation intentions was introduced (Gollwitzer, 1999), which is necessary for a refined concept of action planning. Milne, Orbell, and Sheeran (2002), for example, used planning to increase subsequent exercise behavior reported by students 1 week later. Students were asked to write down when (day or days and time of day) and where they would partake in physical exercise. These participants were more likely to actually exercise, compared with control persons who were equally motivated to exercise but who did not specify their plans. Selfreported planning was found to mediate the relations between intentions and physical activity among students (Norman \& Conner, 2005)

Planning is more than simply an extension of an intention because it includes situation parameters ("when," "where") and a preprogrammed sequence of action ("how"). It is more effective than intentions when it comes to the likelihood and speed of performance, mainly because the behavior is being elicited almost automatically when the relevant situational cues are encountered (Scholz, Sniehotta, Burkert, \& Schwarzer, in press). People do not forget their intentions easily when specified in a when, where, and how manner (for an overview and meta-analysis, see Sheeran, 2002). Therefore, the general emphasis of the present study lies on the assumption that action plans constitute a valuable proximal construct by moving further into the volition phase and by allowing a better prediction of behaviors. 


\section{Universality of Health Behavior Models}

Current health behavior models, such as the HAPA, implicitly presume that behavior can be predicted on the basis of core social-cognitive variables, irrespective of participants' socialcultural background, gender, or age. These factors are either not explicitly included in these models, or they represent distal background variables, exerting their influence through the more proximal social-cognitive variables. Consequently, one could argue that these models implicitly assume that they are likewise applicable in different age groups or cultures. Most studies have been conducted with Western samples, raising the question of whether these models are also predictive in Eastern societies. In the context of physical activity, the first studies have yielded supporting evidence for this contention. Shin, Yung, Pender, and Jang (2005) found in a sample of South Korean adults suffering from a chronic disease that there was a positive relationship between the commitment to an exercise plan and the perceived benefits and barriers of exercise and perceived exercise self-efficacy. Similar results have been reported for South Korean adolescents (Y. H. Kim, 2004) and Chinese undergraduate students (Callaghan, Eves, Norman, Chang, \& Lung, 2002). However, these studies used a crosssectional design, limiting the interpretation of the results. Our study examines whether a comprehensive model like the HAPA is of predictive value for health-promoting behaviors, for example physical exercise in an Eastern culture (South Korea) that has a morbidity and mortality pattern comparable to Western countries.

\section{Age and Health Behavior Change: Differential Effects in Different Age Groups?}

Another important factor that might limit the universality of social-cognitive health behavior models, such as the HAPA, are differences in participants' ages. Physical health undergoes lifelong development and change (Penny, Bennett, \& Herbert, 1994; Spiro, 2001) and, similarly, health becomes an increasingly important life goal with advancing age (Hooker \& Kaus, 1994; Nurmi, 1992; Staudinger, Freund, Linden, \& Maas, 1999). Older adults perceive themselves as being more vulnerable for disease than younger adults (Renner, Knoll, \& Schwarzer, 2000). Moreover, older adults invest more effort to maintain good health by adhering to a healthier lifestyle, and they also tend to eat a healthier diet and to drink and smoke less than younger adults (Leventhal \& Prochaska, 1986). However, they are less physically active in comparison with younger adults (Breuer, 2005; U.S. Department of Health and Human Services, 1999). Thus, during the course of one's life, objective and subjective health as well as health behaviors change with age.

From a life-span perspective, the "aging self" can best be understood in terms of motivational changes (including both personal goals and motivational processes) that occur along with age-related changes in internal and external resources (Brandtstädter, 1998; Freund \& Ebner, 2005). Motivation across adulthood shifts from gain orientation to maintenance orientation and loss avoidance. Beyond middle age, people turn to maintaining performance and healthy functioning in the face of loss and decline (Freund \& Baltes, 2000; Heckhausen, 1999). In particular, younger adults report more gain-striving and fewer loss-avoiding goals, whereas older adults tend to report more goals aimed at preventing losses (Freund, 2006; Heckhausen, 1997). In a similar vein, Lockwood, Chasteen, and Wong (2005) observed that role models, suffering from negative health impacts due to an unhealthy lifestyle, exerted a more motivating effect on older adults than on younger ones. On the basis of these results, one might conclude that older adults' motivation to engage in physical activity is more strongly driven by a health-preventive goal orientation, aiming at maintaining health and decreasing health risks, as compared to younger adults.

However, age differences in health-related domains might already occur between young and middle adulthood. A continuous decline in the major biological systems, such as cardiovascular function, lung volume, or muscle strength, starts at the age of 35 years at the latest (Rybash, Roodin, \& Hoyer, 1995). It is important to note that these physical changes do not imply that people actually feel ill or that they have suffered from a particular disease. Nonetheless, people may notice these physical changes (e.g., decline in muscle strength) and, therefore, become more aware of their susceptibility toward disease in general, which might induce changes in subjective health conceptions and goals. In a previous study with a German sample, we found first evidence for this reasoning (Schwarzer \& Renner, 2000). Moreover, starting in middle age, health becomes an increasingly important life goal (Hooker \& Kaus, 1994; Nurmi, 1992; Staudinger et al., 1999; Staudinger \& Schindler, 2005), and individuals begin to differ in the way they strive for maintenance goals and loss-prevention goals (Ebner, Freund, \& Baltes, 2006).

Accordingly, younger adults appear to perceive themselves as being comparably invulnerable (Renner et al., 2000), and they are less conscious about health-related issues than middle-aged or older adults. Clearly, this line of reasoning does not preclude that middle-aged adults might additionally differ from older adults. Older adults, on average, suffer more frequently from chronic diseases, which has an impact on well-being and self-conceptions. Despite these important differences, however, middle-aged as well as older adults share a higher sense of health awareness and vulnerability, and in this respect they might differ from younger adults.

Vulnerability in conjunction with positive health outcome expectancies and self-efficacy beliefs are commonly seen as a core determinant for intention formation and health behavior change. Thus, the contention is that people become motivated to adopt a health behavior, such as physical exercise, because they feel susceptible and wish to protect themselves against future harm, suggesting that these models might be primarily applicable for middle-aged and older adults. From this perspective, comparing younger adults with middle-aged and older ones appears to be of particular theoretical interest.

Taking into account psychological and physiological changes over the life span, we expected age to affect, in particular, the intention formation in the preintentional motivation phase. Consequently, risk perception might be more influential in middle-aged and older adults. In a similar vein, health-related outcome expectancies might contribute more to intention building in the group of middle-aged and older adults than in the group of younger adults. Because self-regulatory skills are needed for the execution of physical activity, regardless of the intention level, no age differences were expected in the postintentional volition phase as well as in the relationship between self-efficacy and intention. 


\section{Aims of the Study}

One aim of our study is to examine whether the HAPA constitutes a model that can be applied successfully to various behaviors and various cultures, with physical activity in South Koreans chosen as an example. The other aim is to examine whether the HAPA model generalizes to different age groups. Specifically, the following research questions have been posed: (a) Does a structural equation model, specified in terms of the HAPA model, fit the data equally well in two age groups? (b) Do the prediction patterns differ between younger and middle-aged/older adults?

\section{Method}

\section{Participants}

Residents of Seoul and Kyungki-do, South Korea, were invited to participate in a public health screening. Volunteers were recruited from public places such as universities, homes for the elderly, clerical institutions, and police departments. They were examined by medical staff (height, weight, systolic and diastolic blood pressure, total cholesterol), and they received a detailed questionnaire that included items assessing social-cognitive variables and health behaviors. Of 1,359 persons who participated in Wave 1, those 697 who also completed the questionnaire 6 months later at Wave 2 were included in the present study. Within this final sample, 315 participants were men and 358 were women (24 participants did not indicate their gender). Eight participants were identified as multiple outliers and were removed from the multivariate analysis. Average age was 32 years $(S D=17.5$ years $)$, with a range from 16 to 90 years (6 participants did not indicate their age). Sixty-nine percent of the participants were single and $31 \%$ were married. Ten percent were employed in white-collar jobs, $19 \%$ were employed in blue-collar jobs, $6 \%$ were unemployed, $33 \%$ were students, $14 \%$ were homemakers, and $18 \%$ reported that their current employment status did not belong to one of the previously listed categories. Eight percent were without a high school diploma, 57\% had completed high school, and 35\% had a college or university degree. Thus, the sample was well educated, which reflects the high school enrollment rate and high school advancement rate in South Korea (Organisation for Economic Co-operation and Development, 2005). With regard to income, $8 \%$ of participants reported having 500,000 Won or less (below \$545) per month as household income, $17 \%$ had a monthly household income in the range of 510,000 to $1,500,000$ Won $(\$ 546-\$ 1,600)$, $49 \%$ of participants had a monthly household income in the range of $1,510,000$ to $3,000,000$ Won $(\$ 1,617-\$ 3,213)$, and $26 \%$ of participants had a household income of more than $3,100,100$ Won per month (more than $\$ 3,215$ ).

Attrition from Wave 1 to Wave 2 was $49 \%$ ( $n=662 ; 368$ women, 291 men, 3 participants did not indicate their gender), which is considerable but typical for voluntary public health screenings (cf. Glanz \& Gilboy, 1995). In order to investigate whether the longitudinal subsample was representative of the initial sample, we compared the Wave 1 responses of the final longitudinal sample $(N=697)$ to the responses of the dropout sample $(n=662)$. The longitudinal sample was slightly younger than the dropout sample $(M=31.8$ years vs. $M=35.4$ years $)$, $t(1357)=4.0, p<.01$. No significant differences were found with regard to risk perception, outcome expectancies, action self- efficacy, coping self efficacy, and planning. However, there were small albeit significant differences in physical activity intentions, $t(1117)=2.30, p<.05$, and physical activity $t(1107)=2.03, p<$ .05 , indicating that the longitudinal sample had weaker intentions to be physically active $(M=4.61, S D=1.94$ vs. $M=4.84, S D=$ $1.43)$ and was more physically active at baseline than the dropout sample $(M=5.01, S D=4.85$ vs. $M=4.42, S D=4.78)$.

To examine whether age groups vary in their motivational structure, we dichotomized the continuous age variable with a cut-off value of 35 years, resulting in samples of younger adults $(n=489, M=22.6, S D=5.1)$, and middle-aged/older adults $(n=$ 202, $M=55.2, S D=13.5)$.

\section{Measures}

All scales were translated from German into Korean by bilingual and bicultural individuals and native-language speakers, and they were verified through back translations (Behling \& Law, 2000). ${ }^{1}$ They were then tested in a pilot study with respect to ambiguity, plausibility, and difficulty in order to reduce the frequency of invalid responses (cf. Clark \& Watson, 1995). Risk perception, outcome expectancies, action self-efficacy, and intention were assessed at Wave 1; planning, coping self-efficacy, and physical activity were assessed at Wave 2. Unless stated otherwise, all items had a response range from 1 , not at all true, to 4 , exactly true.

Risk perception. The HAPA model assumes that the more people feel at risk for certain diseases, the more likely they are to form an intention to adopt health-promoting behaviors. Accordingly, perceived personal risk of suffering from diseases and risk factors that are linked to physical inactivity were assessed (cf. Perloff \& Fetzer, 1986). Participants were asked to estimate the likelihood of contracting each of the following conditions during their lifetime: hypertension, hypercholesteremia, and cardiovascular diseases. Responses were made on 7-point Likert scales ranging from 1, very unlikely, to 7 , very likely. Internal consistency was Cronbach's $\alpha=.89$.

Outcome expectancies. Outcome expectancies were assessed according to Schwarzer and Renner (2000) with 10 items (Cronbach's $\alpha=.91)$. Participants were asked, "What do you think will be the consequences if you exercise regularly?" Responses were elicited to specific items, such as: "If I exercise regularly, then. . (a) I'll look more attractive, or (b) it would be good for my blood pressure." Five parcels of two items each were used as indicators for outcome expectancies.

Action self-efficacy. Exercise self-efficacy was assessed by two scales from Schwarzer and Renner (2000): action self-efficacy and coping self-efficacy. For the assessment of perceived action self-efficacy at Wave 1, the following three items were used (Cronbach's $\alpha=.86$ ): "Certain barriers make it hard to begin exercising. How sure are you that you can begin exercising regularly? I am sure that. . . (a) I can change to a physically active life style. (b) I can be physically active once a week. (c) I can be physically active at least 3 times a week for 30 minutes each time.'

Coping self-efficacy. For the assessment of perceived coping self-efficacy at Wave 2 (cf. Schwarzer \& Renner, 2000), an 11-

\footnotetext{
${ }^{1}$ All scales are available online: http://www.gesundheitsrisiko.de
} 
item scale was used (Cronbach's $\alpha=.96$ ): "It is important to stay physically active. Are you confident you can manage that?" The item stem, "I am sure I can keep on being physically active regularly, even if. ..," was followed by items concerning typical barriers that may hamper the maintenance of the behavior, such as, ". . I don't see success at once," or "I am tired." Five parcels of two to three items each were used as indicators of coping selfefficacy.

Principal components analysis of all 14 self-efficacy items was computed, with eigenvalue $>1$ as the extraction criterion, yielding two components: 3 items for the action self-efficacy factor, and 11 items for the coping self-efficacy factor. Of the total variance, $70 \%$ was accounted for by this solution. Thus, the analysis confirmed a two-factor solution attesting to the discriminant validity of the two phase-specific self-efficacy constructs.

Intention. One item assessed intention, namely, "I intend to be physically active on a regular basis." Responses were made on 7-point scales ranging from 1, I don't intend to at all, to 7, I strongly intend.

Planning. Planning was assessed with the same technique as Sniehotta et al. (2005). A 5-item scale assessed action planning (Cronbach's $\alpha=.94)$. The item stem "I have made a detailed plan regarding. ..," was followed by the items (a) "... when to do my exercise," and (b) "...where to exercise." Coping planning was assessed by four items (Cronbach's $\alpha=.94$ ). The item stem "I have made a detailed plan regarding. ..," was followed by the items (a) "... what to do if something intervenes," and (b) "... when to especially watch out in order to stay committed." Because these two scales were closely interrelated $(r=.73, p<$ .01 ), they were used jointly as indicators of the planning construct.

Physical activity. For the assessment of physical activity, participants were asked in line with the South Korean National Survey of Sports Participation (cf. M. Kim, 1996) and the European Prospective Investigation into Cancer Study (EPIC) Norfolk Phys- ical Activity Questionnaire (Wareham et al., 2002) how often they engaged in different types of physical activity covering a broad range of aerobic, calisthenics, and resistance activities that are relevant for younger and older adults (see also Netz, Wu, Becker, $\&$ Tenenbaum, 2005). In particular, participants were asked how often they engage in, on average, (a) cycling; (b) endurance activities (jogging, running, swimming, rowing, etc.); (c) walking, hiking; (d) calisthenics, gymnastics, aerobics, dancing; (e) strength and weight training; (f) games (baseball, soccer, volleyball, tennis, squash, etc.); and (g) martial arts (karate, judo, taekwondo, aikido, kendo, kickboxing, boxing, etc.). The answers were given on a 5-point Likert-type scale $(1=$ almost every day, $2=2-3$ times $a$ week, $3=$ once a week, $4=1-3$ times a month, and $5=$ less than once a month or never). Responses were recorded for each activity, respectively, as 0.0, never, 0.5, 1-3 times a month, 1.0, once a week, 2.5, 2-3 times a week, and 5.0, almost every day (see Table 1). Because we were interested in how health-related cognitions motivate people to adopt physical activity independently from the respective type, we collapsed the recoded responses into a total sum score of physical activity per week.

\section{Data Analyses}

Structural equation models were computed with AMOS 5 (Arbuckle, 2003). The model fit was assessed by examining the comparative fit index (CFI), the Tucker-Lewis Index (TLI), and the root-mean-square error of approximation (RMSEA). A model is judged to have a good fit if CFI and TLI indices have values higher than .90 , the value of RMSEA is smaller than .08 , the lower bound of $90 \%$ confidence intervals (CI) is close to zero, and the upper bound of the $90 \%$ CI does not exceed .10 (Tabachnick \& Fidell, 2001). Because the $\chi^{2}$ statistic is sample-size dependent, the $\chi^{2} / d f$ ratio was employed as a further goodness-of-fit criterion. Bollen and Long (1993) suggested a $\chi^{2}$ not larger than 2-5 times

Table 1

Descriptive Statistics for Physical Activities of Younger and Middle-Aged/Older Adults

\begin{tabular}{|c|c|c|c|c|c|c|c|}
\hline \multirow[b]{2}{*}{ Types of physical activity } & \multicolumn{3}{|c|}{$\begin{array}{l}\text { Younger } \\
\text { adults }\end{array}$} & \multicolumn{3}{|c|}{$\begin{array}{l}\text { Middle-aged/ } \\
\text { Older adults }\end{array}$} & \multirow[b]{2}{*}{$F^{\mathrm{b} /} \chi^{2^{\mathrm{c}}}$} \\
\hline & $M$ & $S D$ & $\%^{\mathrm{a}}$ & $M$ & $S D$ & $\%^{\mathrm{a}}$ & \\
\hline \multicolumn{8}{|l|}{ Aerobic } \\
\hline Bicycling (also exercise bike) & 0.44 & 0.95 & 17.9 & 0.48 & 1.22 & 15.2 & $0.2 / 0.5$ \\
\hline Endurance sports (jogging, running, swimming, rowing, etc.) & 0.73 & 1.33 & 27.0 & 0.48 & 1.28 & 13.4 & $3.4 / 9.8^{* *}$ \\
\hline Walking, hiking & 1.91 & 1.87 & 61.0 & 1.84 & 1.92 & 54.5 & $0.1 / 1.8$ \\
\hline \multicolumn{8}{|l|}{ Calisthenics } \\
\hline Calisthenics, gymnastics, aerobics, dancing & 0.76 & 1.40 & 29.3 & 0.71 & 1.34 & 25.6 & $0.2 / 0.7$ \\
\hline Resistance training & & & & & & & \\
\hline Strength and weight training & 0.61 & 1.19 & 23.8 & 0.31 & 1.05 & 9.7 & $6.2^{*} / 11.6^{* *}$ \\
\hline \multicolumn{8}{|l|}{ Aerobic-resistance } \\
\hline $\begin{array}{l}\text { Games (baseball, soccer, volleyball, tennis, handball, basketball, squash, } \\
\text { badminton, etc.) }\end{array}$ & 0.79 & 1.27 & 28.5 & 0.53 & 1.33 & 12.5 & $3.9^{*} / 13.4^{* *}$ \\
\hline Martial arts (karate, judo, taekwondo, aikido, kendo, kickboxing, boxing, etc.) & 0.27 & 0.81 & 10.6 & 0.09 & 0.55 & 2.4 & $5.4 / 8.1^{* * *}$ \\
\hline Total physical activity score & 5.33 & 5.24 & 83.0 & 3.92 & 4.73 & 76.3 & $8.4^{* * *} / 3.3$ \\
\hline
\end{tabular}

Note. Coding of physical activity measure: $0.0=$ never, $0.5=1-3$ times a month, $1.0=$ once a week, $2.5=2-3$ times a week, and $5.0=$ almost every day.

${ }^{a}$ Percentage of participants who performed the respective physical activity at least once a week. ${ }^{\mathrm{b}} F$ test for age differences in the mean physical activity per week. $\quad{ }^{\mathrm{c}} \chi^{2}$ test for age differences in percentage of participants who performed the respective physical activity at least once a week $p<.05 .{ }^{* *} p<.01$. 
the degrees of freedom. Treatment of missing values was done by the full information maximum likelihood method. This method is seen as an excellent imputation algorithm if values are missing at random (Schafer \& Graham, 2002), which was the case in our data.

For all constructs except risk perception, action self-efficacy, and intentions, parcels were used to create indicators for latent variables within a structural equation approach. Parcels are sums or averages of two or more items of a construct. They have a lower error variance and are, thus, more reliable than single indicators (Bandalos \& Finney, 2001; MacCallum, Widaman, Zhang, \& Hong, 1999). For parceling, the random assignment method suggested by Little, Cunningham, Shahar, and Widaman (2002) was used. Because all single-item loadings were equally high, and all latent constructs were one-dimensional, parcel composition did not affect the interpretation of the latent construct.

\section{Results}

From a life-span perspective, age-related differences in motivational orientation were expected. Thus, in a first step, mean level differences in health cognitions and behavior were investigated. Analyses showed, in accordance with previous research, that middle-aged/older adults $(n=202)$ perceived themselves as being more vulnerable for cardiovascular diseases than younger adults $(n=489 ; M=3.89$ vs. $M=3.46), F(1,509)=11.5, p<.01$. Moreover, they had a stronger intention to be physically active $(M=4.93$ vs. $M=4.48), F(1,609)=6.6, p<.01$. They also demonstrated greater action self-efficacy than younger adults $(M=3.27$ vs. $M=3.12), F(1,586)=4.5, p<.05$. Younger and middle-aged/older adults did not differ in terms of any other variable (cf. Table 2).

However, as expected, middle-aged/older adults were physically less active than younger adults $(M=3.92$ vs. $M=5.33), F(1$, $568)=8.4, p<.01$. As Table 1 shows, in terms of the two most frequently performed activities (walking/hiking and calisthenics), no differences were found between the two age groups. However, significant differences for four activities (endurance activities, strength and weight training, games, and martial arts) between the two age groups emerged, indicating that younger adults chose these types more often (all $\chi^{2}>8.0, p<.01$ ). For the following analyses, the average sum score of physical activity per week was used.

In a second step, relations between social-cognitive variables and physical activity were investigated. Table 3 presents the intercorrelations for the latent variables risk perception, outcome expectancies, action self-efficacy, and intention that were assessed at Wave 1, and for the latent variables planning, coping selfefficacy, and physical activity that were assessed at Wave 2. The correlations revealed the expected pattern of results. The intention to exercise was positively associated with outcome expectancies and action self-efficacy. However, there was no significant relationship between risk perception and the intention. Physical activity was associated with action self-efficacy, coping self-efficacy, and planning, but not with intention.

A structural equation model was specified with self-reported physical activity as the endogenous latent variable; intention, planning, and coping self-efficacy as mediators; and risk perception, outcome expectancies, and action self-efficacy as exogenous variables. The applicability of the HAPA model in the domain of physical activity was examined for different age groups via multiple-group comparison (cf. Byrne, 2001).

In a first step, the HAPA model was tested separately for each age group. The model for younger adults yielded a reasonable fit to the data, $\chi^{2}(164)=528.8 ; p<.01 ; \chi^{2} / d f=3.22 ; \mathrm{CFI}=.91$; $\mathrm{TLI}=.88 ;$ RMSEA $=.068 ; 90 \% \mathrm{CI}=.062, .075$. The fit of the model for middle-aged/older adults was also satisfactory, $\chi^{2}(164)=261.9 ; p<.01 ; \chi^{2} / d f=1.60 ;$ CFI $=.94 ;$ TLI $=.92 ;$ RMSEA $=.055 ; 90 \% \mathrm{CI}=.043, .067$. Thus, the hypothesized model represented the data well within each age group (see also Figure 1).

Moreover, the predicted relationships were confirmed: A large amount of variance was accounted for within the middle-aged/ older sample, $20 \%$ of physical activity, $55 \%$ of planning, and $19 \%$ of intention variance. In the younger sample, the corresponding amounts were only $6 \%$ of physical activity, $4 \%$ of planning, and $3 \%$ of intention variance. The question of whether age moderates the specified relations was investigated in the next set of analyses.

To investigate whether the structure of social-cognitive variables differed between age groups, we pursued multiple-group

Table 2

Descriptive Statistics for Social-Cognitive Variables for Younger Adults and Middle-Aged/Older Adults

\begin{tabular}{|c|c|c|c|c|c|c|}
\hline \multirow[b]{2}{*}{ Social-cognitive variable } & \multicolumn{2}{|c|}{$\begin{array}{l}\text { Younger } \\
\text { adults }\end{array}$} & \multicolumn{2}{|c|}{$\begin{array}{l}\text { Middle-aged/ } \\
\text { Older adults }\end{array}$} & \multirow[b]{2}{*}{$F$} & \multirow[b]{2}{*}{$p$} \\
\hline & $M$ & $S D$ & $M$ & $S D$ & & \\
\hline \multicolumn{7}{|c|}{ Time 1} \\
\hline Risk perception & 3.46 & 1.29 & 3.89 & 1.25 & 11.5 & $<.01$ \\
\hline Outcome expectancies & 3.31 & 0.52 & 3.36 & 0.58 & 1.0 & $n s$ \\
\hline Action self-efficacy & 3.12 & 0.72 & 3.27 & 0.75 & 4.5 & $<.05$ \\
\hline Intention & 4.48 & 1.95 & 4.93 & 1.89 & 6.6 & $<.01$ \\
\hline \multicolumn{7}{|c|}{ Time 2} \\
\hline Coping self-efficacy & 2.64 & 0.56 & 2.70 & 0.67 & 1.2 & $n s$ \\
\hline Planning & 2.49 & 0.64 & 2.53 & 0.72 & 0.4 & $n s$ \\
\hline
\end{tabular}


Table 3

Correlations Between Physical Activity and Social-Cognitive Variables

\begin{tabular}{|c|c|c|c|c|c|c|c|}
\hline Social-cognitive variable & 1 & 2 & 3 & 4 & 5 & 6 & 7 \\
\hline 1. Risk perception & - & & & & & & \\
\hline 2. Outcome expectancies & -.03 & - & & & & & \\
\hline 3. Action self-efficacy & -.02 & $.46^{*}$ & - & & & & \\
\hline 4. Intentions & .01 & $.13^{*}$ & $.22^{* *}$ & - & & & \\
\hline 5. Planning & .01 & $.14^{*}$ & $.30^{\text {*** }}$ & $.20^{*}$ & - & & \\
\hline 6. Coping self-efficacy & .00 & $.16^{*}$ & $.27^{* *}$ & $.18^{*}$ & $.73^{* *}$ & - & \\
\hline 7. Physical activity & -.04 & .07 & $.18^{* *}$ & -.04 & $.26^{* * *}$ & $.30^{* * *}$ & - \\
\hline
\end{tabular}

analyses further. In particular, a sequence of nested models testing for group differences was examined (cf. Table 4). In a first step, the baseline model (M1) was tested in both age groups simultaneously. The fit of this simultaneously estimated model provided the baseline value against which all specified models were subsequently compared. This multiple-group model reflects the extent to which the structure of the HAPA model fits the data when no cross-group constraints are imposed. The goodness-of-fit indices for the models with different constraints are summarized in Table 4. The fit indices for the overall baseline model indicate that the hypothesized HAPA structure is well represented within the total sample, $\chi^{2}(326)=790 ; p<.01 ; \chi^{2} / d f=2.43 ;$ CFI $=.92 ;$ TLI $=$ .89 ; RMSEA $=.046 ; 90 \% \mathrm{CI}=.042, .050$.

In a second step, measurement invariance between age groups was investigated. Thus, the question of whether items or parcels assess the same constructs in different age groups was examined.
A common practice is to constrain the factor loadings to be equal across samples and then to constrain factor variances (cf. Byrne, 2001). By additionally constraining factor variance, the equality in factor variability between age groups can be tested. Accordingly, a model (M2) constraining all factor loadings to be equal was tested against model M1, which allowed the factor loadings to vary across subsamples. With a $\Delta \chi^{2}(13)=11.25, p=.59$, the assumption of factorial invariance across different age groups was confirmed. Then, in a third step, model M2 was tested against a model (M3) that additionally constrained the factorial variance. Again, no difference between groups was found, $\Delta \chi^{2}(3)=1.65, p=.64$.

After the measurement model equivalence across age groups was substantiated, the invariance (i.e., equivalence) of the structural model across groups was investigated in a fourth step. Accordingly, a model (M4) fixing all regression weights to be equal across groups was tested against model M3. If the nested-model

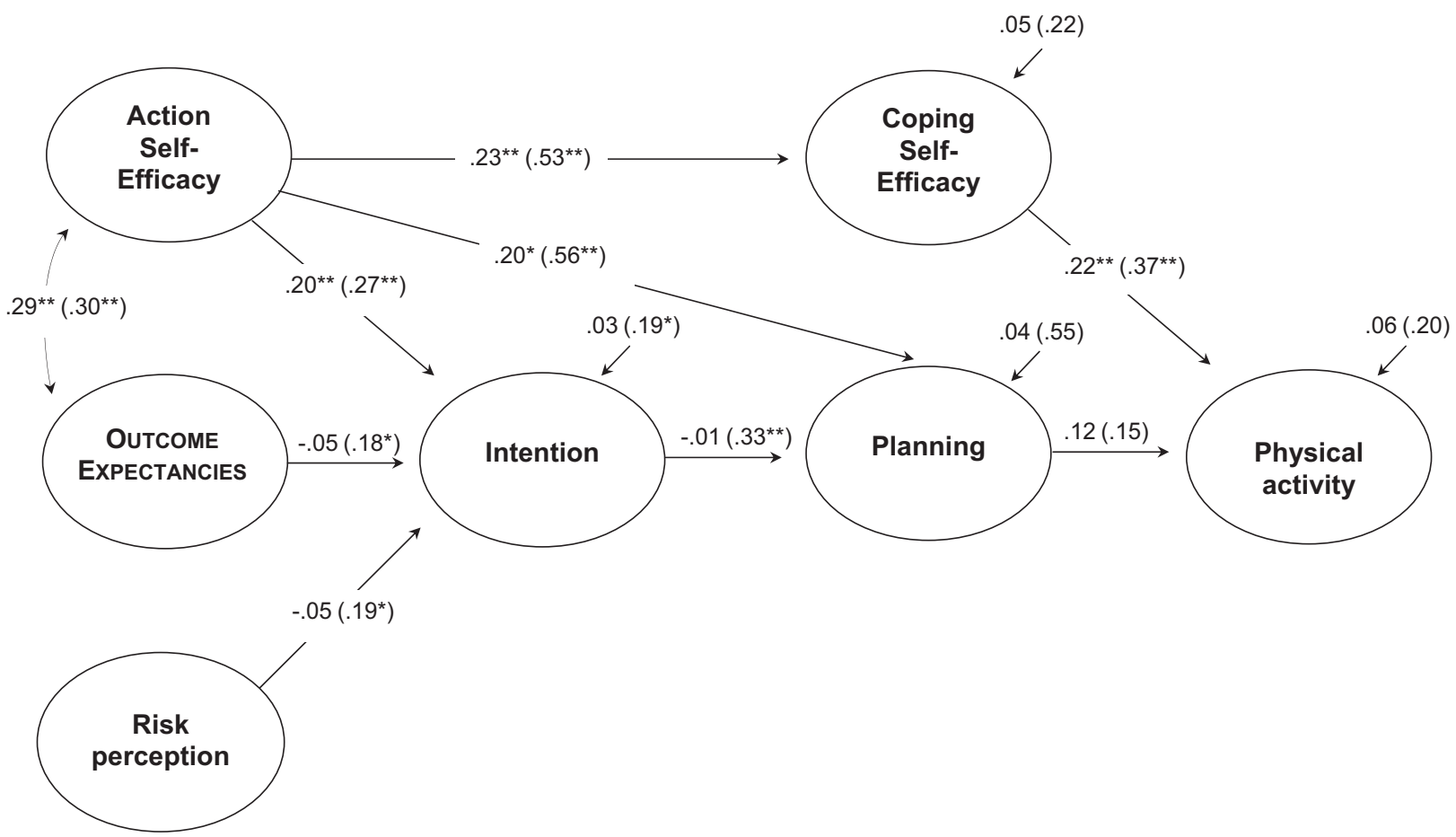

Figure 1. Two-group prediction model for physical activity in South Koreans (coefficients for older adults in parentheses). ${ }^{*} p<.05 .{ }^{* *} p<.01$. 
Table 4

Goodness-of-Fit Indices for Nested Models

\begin{tabular}{|c|c|c|c|c|c|c|c|c|c|}
\hline Model & $\Delta \chi^{2}(d f ; p)$ & $x^{2}$ & $d f$ & $p$ & $\chi^{2} / d f$ & CFI & TLI & RMSEA & CI $90 \%$ \\
\hline Baseline (M1) & & 790.88 & 326 & $<.01$ & 2.43 & .92 & .89 & .046 & $.042, .050$ \\
\hline Constrained factor loadings (M2) & $11.25(13 ; n s)$ & 802.13 & 339 & $<.01$ & 2.37 & .92 & .90 & .045 & $.041, .049$ \\
\hline Constrained factor variance (M3) & $1.65(3 ; n s)$ & 803.78 & 342 & $<.01$ & 2.35 & .92 & .90 & .044 & $.040, .048$ \\
\hline Constrained regression weights (M4) & $46.04(8 ;<.01)$ & 849.82 & 350 & $<.01$ & 2.43 & .91 & .89 & .046 & $.042, .050$ \\
\hline
\end{tabular}

Note. $\quad \mathrm{CFI}=$ comparative fit index; $\mathrm{TLI}=$ Tucker-Lewis Index; RMSEA $=$ root-mean-square error of approximation; $\mathrm{CI}=$ confidence interval; $\mathrm{M} 1=$ Model 1; M2 = Model 2; M3 = Model 3; M4 = Model 4.

comparison suggests a significant difference between these two models, the patterns of social-cognitive variables between younger and older adults can be regarded as being different. The results were significant, $\Delta \chi^{2}(8)=46.04, p<.01$, indicating structural differences in the prediction pattern of physical activity between age groups. In order to pinpoint the source of age differences, single path differences were investigated in the following step.

By examining group differences in single paths, we identified the unique prediction patterns for age groups. This was done by setting equality constraints on each single path and comparing this model to model M3. Significant differences between groups were found in the following regression weights: risk perception on intention, $\Delta \chi^{2}(1)=2.69, p=.10$; outcome expectancies on intention, $\Delta \chi^{2}(1)=4.10, p<.05$; intention on planning, $\Delta \chi^{2}(1)=$ $4.65, p<.05$; action self-efficacy on planning, $\Delta \chi^{2}(1)=14.40$, $p<.01$; and action self-efficacy on coping self-efficacy, $\Delta \chi^{2}(1)=$ $10.50, p<.01$. Figure 1 displays the standardized solution.

As these results show, there were significant differences between the middle-aged/older adults and younger adults in the motivation to be physically active. For younger adults, action self-efficacy alone was sufficient for the intention formation. In the group of middle-aged/older adults, all three health cognitions (risk perception, outcome expectancies, and action self-efficacy) facilitated intention formation. Further, additional mediation analysis (Baron \& Kenny, 1986) showed that in the group of younger adults, the precondition for mediation analysis, namely the significant association between intention and physical activity, was not fulfilled $(r=.05, n s)$. Thus, physical activity in this age group is likely to be performed for reasons other than health-related ones. In the group of middle-aged/older adults, the mediation analysis revealed a significant decrease in the association between intention and physical activity when planning was entered into the regression equation $\left(\beta_{\text {before }}=.20, p<.01 ; \beta_{\text {after }}=.06, n s\right.$; Sobel test $Z=3.55, p<.01)$.

Various studies on general self-regulation and personal goals showed that goal orientation and self-regulatory processes change from early to late adulthood (Heckhausen, 1997). Interestingly, recent studies have suggested that this change (e.g., motivational selectivity) accelerates beginning with the transition from middle to later adulthood (Baltes \& Smith, 2003; Freund \& Riediger, 2003; Riediger \& Freund, 2006). Following this line of contention, we tested in additional control analyses the assumption that the observed differences between young adults compared to middle-aged/older adults were driven by a distinctive pattern of results in older adults. If age differences are predominately driven by older adults, age differences should quadratically increase from early to later adulthood and contribute to differences in preintentional motivation processes (cf. Riediger \& Freund, 2006). A further alternative assumption is that age differences in the HAPA model variables are linear and therefore increase with age. To model these assumptions of linearity and nonlinearity in the associations between age and the variables of the HAPA model, we included two age indicators in the overall HAPA model: participants' raw age (in years) and the squared term of participants' age. To avoid specification problems due to linear dependencies among variables, we followed recommendations by Kline and Dunn (2000) and derived the squared age term from the grand-mean-centered age distribution $(r=.69, p<.01)$.

Additionally, including the raw age term and the squared age term in the overall HAPA model yielded a reasonable fit of the data, $\chi^{2}(189)=629.73 ; p<.001 ; \chi^{2} / d f=3.33 ; \mathrm{CFI}=.93 ; \mathrm{TLI}=$ $.90 ; \mathrm{RMSEA}=.058 ; 90 \% \mathrm{CI}=.053, .063$. However, the squared age term-related parameter estimates were only significant in two instances $(p s<.05)$ : Intention $(-.13)$ and physical activity $(-.16)$ were significantly related to the squared age term. Similarly, the raw age term was only significantly related to risk perception (.25) and to intention $(.18 ; p \mathrm{~s}<.05)$. Hence, neither the assumption that age differences accelerate with increasing age nor the assumption that there is a linear increase over the life span were unequivocally supported by the data.

In order to more secure the assumption of age differences between younger adults and middle-aged/older adults, we pursued additional multiple-group analyses. In particular, we examined whether younger adults (35 years or younger) and middle-aged adults (36-55 years) differ significantly. The fit indices for the simultaneously estimated (baseline) model indicate that the hypothesized HAPA structure is well-represented across both age groups, $\chi^{2}(371)=877 ; p<.001 ; \chi^{2} / d f=2.36 ;$ CFI $=.90 ;$ TLI $=$ .89 ; RMSEA $=.048 ; 90 \% \mathrm{CI}=.044, .052$. However, testing the invariance of the structural model across groups indicated structural differences in the prediction pattern of physical activity between age groups, $\Delta \chi^{2}(8)=47.55, p<.001$. Examining group differences in single paths yielded comparable significant differences in regression weights between groups as in the full sample model (risk perception on intention, outcome expectancies on intention, intention on planning, action self-efficacy on planning, and action self-efficacy on coping self-efficacy; all $\Delta \chi^{2}(1)>5$, $p s<.05)$. Thus, the pattern of results remained stable even when excluding older adults (56 years and older), suggesting differences between earlier and middle adulthood in terms of health behavior motivation. 


\section{Discussion}

Previous research has demonstrated that the HAPA is valid for various health behaviors (Schwarzer et al., 2007). One goal of the present study was to examine whether the HAPA could also be applied successfully to various cultures, with physical activity in South Koreans chosen as an example. In general, the overall model fitted the data, replicating and extending previous patterns of results found for dietary behaviors (Schwarzer \& Renner, 2000). This provides first evidence for the contention that the HAPA reflects a pattern of relationships that might be universal and could serve as a template to understanding health behavior change in various cultures. Further replications in additional cultures and with other health behaviors are needed to substantiate the present results.

The other goal was to examine whether the HAPA model generalizes to different age groups. Extending the traditional view that intentions are the best predictors of behavior (Fishbein \& Ajzen, 1975), the present results demonstrate that for the middle-aged/older adult sample, in accordance with previous studies, postintentional constructs seem to be appropriate to allow for a more direct prediction of behavior. To bridge the intention-behavior gap, researchers have found self-efficacy and planning to be useful (Lippke et al., 2004; Scholz, Sniehotta, \& Schwarzer, 2005; Schwarzer \& Renner, 2000; Sniehotta et al., 2005; Ziegelmann et al., 2006). The present data underscore this position, in particular in favor of coping selfefficacy. The latter appears to be the best direct predictor of physical activity. This is theoretically meaningful since intenders face unforeseen barriers and are challenged by temptations. One's confidence in being able to meet such demands motivates individuals to invest more effort and to persist longer when it comes to translating intentions into action.

Age differences in the interplay of social-cognitive variables were found. The model showed a good fit in the middle-aged/ older adult sample, whereas it seemed to be less applicable to younger adults (below the age of 35 years). Almost no variance of intentions, planning, and behavior was accounted for by the model within the younger adult subsample. In contrast, for those over 35 years, $19 \%, 55 \%$, and $20 \%$ of the variance in these three variables were accounted for, respectively. Previous applications of the HAPA to physical activity were conducted in older rehabilitation patients. In the study by Sniehotta et al. (2005), for example, participants were on average 59 years old. Likewise, in the study by Lippke et al. (2004), the average age was 47 years. The present results suggest that the HAPA might be less applicable in the domain of regular physical activity in a relatively young and healthy sample as compared to older rehabilitation patients with an explicit medical recommendation to improve their fitness. Supporting this notion, similar age differential effects were obtained for dietary behaviors (Schwarzer \& Renner, 2000). In particular, it was found that risk perception was associated with intention formation in older adults only, not in younger ones. One reason for the observed age differential effects could be that physical activity is regarded as an explicit health behavior by the middle-aged/older group, whereas it is considered a lifestyle factor by the younger ones. That is, physical activity is generated by social influence and daily leisure habits, not guided by particular health con- cerns. This line of reasoning is supported by the present result that risk perception was related to activity intentions only within the middle-aged/older sample. Moreover, additional analyses on subjective health and reported health complaints showed accordingly that middle-aged/older adults perceived a poorer health status than younger ones, $t(687)=27.22, p<.01$, and reported cardiovascular diseases more often, $\chi^{2}(1)=14.08$, $p<.01$. Experiencing health problems and diseases may generally increase health concerns and risk perceptions that lead to a higher intention of performing health-promoting behaviors, such as physical activity. Finally, the middle-aged/older adults were less likely to engage in activities for the benefit of enjoyment, such as martial arts or sporting games, than younger adults, further supporting the notion that the intention of performing physical activity is more likely to be guided by health concerns for the middle-aged/older adults in comparison to the younger adults. However, both forms of self-efficacy emerged as the major determinants of reported physical activity in the older and younger groups, indicating that self-regulatory skills are a prerequisite for successful performance (see also Netz et al., 2005).

For future research addressing age-specific implications in promoting physical exercise, it would be fruitful to consider employing an explicit stage approach by dividing both samples into nonintenders, intenders, and actors, and applying agespecific tailored interventions. Risk communication might be suitable in older nonintenders, whereas younger nonintenders might not respond to such an intervention because their physical exercise is less determined by health concerns. In older intenders, strategic planning interventions might be appropriate. In younger intenders, social influence could be a possible candidate to translate their intentions into action. However, this remains speculative because social network variables were not assessed in the present study.

Considering that most studies on health behavior change were conducted within Western samples, these results extend previous research by suggesting that the HAPA may also be valid in non-Western samples. Moreover, age-related changes in the personal goal orientation seem to evoke stronger differential effects than cultural differences do. However, multiple group comparisons of the model between representative samples from different cultures have not yet been performed. Therefore, these conclusions are tentative.

Additionally, limitations of the present study need to be acknowledged. The present analyses are based on longitudinal data, whereby the relations between a baseline assessment of socialcognitive variables and, 6 months later, proximal volitional predictors along with physical activity were assessed. In all domains of human functioning, baseline behaviors, however, are typically the best predictors of later behaviors. The debate about the role of past behavior is controversial. One could argue from a theoretical point of view that baseline behaviors are themselves a product of previous social-cognitive-behavioral processes leading inevitably to an infinite regress (Bandura, 1997). Accordingly, including past behavior may mask the theoretically more important effects of social-cognitive variables without leading to further insights into the processes that lead to the behavior. However, in our study, a separate analysis including past behavior as an additional predictor for behavior did not change the observed pattern of results, indi- 
cating that social-cognitive variables accounted for physical activity above and beyond past behavior. ${ }^{2}$

Furthermore, the criterion variable (physical activity) is selfreported, and there is no direct possibility to examine the validity of these self-reports. However, there is evidence for the validity of physical activity self-reports (Miller, Freedson, \& Kline, 1994).

Another limitation of the internal and external validity of our study is that participants were volunteers. Consequently, the degree to which the findings generalize to those persons who did not participate is limited. Although typical for public screening studies with volunteers (cf. Glanz \& Gilboy, 1995), a clear restriction for the external validity might be that the attrition rate between the first and second wave led to a systematic sample bias. However, control analyses showed that the dropouts and the study sample did not differ systematically in variables under study (i.e., perceived risk, outcome expectancies), except that the dropouts had higher intentions and were less physically active.

In sum, we have examined the applicability of the HAPA model in predicting physical activity in a large South Korean sample. Substantial age differences have been unveiled that need to be subjected to further inquiry. Our study confirms the usefulness of the HAPA model for the subsample of middle-aged and older persons (beyond the age of 35 years), but not for the younger sample. The findings bear implications for both theory building and health interventions. The basic contention that people become motivated to adopt health behaviors because they feel susceptible to illness and want to protect themselves against future harm might be predominately applicable for middle-aged and older adults, and to a lesser degree for younger adults. Considering the insights from life-span psychology, it seems reasonable to adjust current health behavior models to the uniqueness of different groups. Middleaged/older adults might be more strongly driven by a healthpreventive goal orientation, aiming at maintaining health and decreasing health risks, as compared to younger adults. Thus, interventions might be more effective if they target particular age groups. Messages aimed at risk perception and health-related outcome expectancies might be more effective in middle-aged/older adults than in younger adults, whereas those stressing action and coping self-efficacy might be effective in all age groups.

\footnotetext{
${ }^{2}$ Additional analysis including the baseline measure of physical activity yielded, for both models, a reasonable fit, $\chi^{2}(202)=612.9 ; p<.01$; $\chi^{2} / d f=3.03 ; \mathrm{CFI}=.91 ; \mathrm{TLI}=.88 ; \mathrm{RMSEA}=.065 ; 90 \% \mathrm{CI}=.059, .071$ for younger adults; and $\chi^{2}(182)=319.6 ; p<.01 ; \chi^{2} / d f=1.75 ; \mathrm{CFI}=.92$; TLI $=.90 ;$ RMSEA $=.062 ; 90 \% \mathrm{CI}=.050, .073$ for middle-aged/older adults. As expected, a significant relationship between physical activity at baseline and 6 months later emerged $(\beta=.47$ for young adults and $\beta=$ .48 for middle-aged/older adults). Through inclusion of past behavior, a higher proportion of variance in physical activity was accounted for $\left(R^{2}=\right.$ .27 for younger adults and $R^{2}=.33$ for middle-aged/older adults). Most important, however, including the baseline behavior did not change the overall prediction pattern.
}

\section{References}

Abraham, C., \& Sheeran, P. (2000). Understanding and changing health behavior: From health beliefs to self-regulation. In P. Norman, C. Abraham, \& M. Conner (Eds.), Understanding and changing health behavior (pp. 3-24). Amsterdam: Harwood.
Arbuckle, J. L. (2003). Amos 5.0 user guide. Chicago: Small Waters.

Armitage, C. J. (2004). Evidence that implementation intentions reduce dietary fat intake: A randomized trial. Health Psychology, 23, 319-323.

Baltes, P. B., \& Smith, J. (2003). New frontiers in the future of aging: From successful aging of the young old to the dilemmas of the fourth age. Gerontology, 49, 123-135.

Bandalos, D. L., \& Finney, S. J. (2001). Item parceling issues in structural equation modeling. In G. A. Marcoulides \& R. E. Shumaker (Eds.), Advanced structural equation modeling: New developments and techniques (pp. 269-296). Mahwah, NJ: Erlbaum.

Bandura, A. (1997). Self-efficacy: The exercise of control. New York: Freeman.

Bandura, A. (2000). Health promotion from the perspective of social cognitive theory. In P. Norman, C. Abraham, \& M. Conner (Eds.), Understanding and changing health behavior: From health beliefs to self-regulation (pp. 299-339). Amsterdam: Harwood.

Baron, R. M., \& Kenny, D. A. (1986). The mediator-moderator variable distinction in social psychological research: Conceptual, strategic, and statistical considerations. Journal of Personality and Social Psychology, 51, 1173-1182.

Behling, O., \& Law, K. S. (2000). Translating questionnaires and other research instruments: Problems and solutions. Thousand Oaks, CA: Sage.

Bollen, K., \& Long, J. (Eds.). (1993). Testing structural equation models. Thousand Oaks, CA: Sage.

Brandtstädter, J. (1998). Action theory in developmental psychology. In R. M. Learner (Ed.), Handbook of child psychology: Vol. 1. Theoretical models of human development (5th ed., pp. 807-863). New York: Wiley.

Breuer, C. (2005). Cohort effects in physical inactivity: A neglected category and its health economical implications. Journal of Public Health, 13, 189-195.

Byrne, B. M. (2001). Structural equation modeling with AMOS: Basic concepts, applications, and programming. Mahwah, NJ: Erlbaum.

Callaghan, P., Eves, F. E., Norman, P., Chang, A. M., \& Lung, C. Y. (2002). Applying the transtheoretical model to exercise in young Chinese people. British Journal of Health Psychology, 7, 267-282.

Clark, L. A., \& Watson, D. (1995). Constructing validity: Basic issues in objective scale development. Psychological Assessment, 7, 309-319.

Ebner, N. C., Freund, A. M., \& Baltes, P. B. (2006). Developmental changes in personal goal orientation from young to late adulthood: From striving for gains to maintenance and prevention of losses. Psychology and Aging, 21, 664-678.

Fishbein, M., \& Ajzen, I. (1975). Belief, attitude, intention, and behavior: An introduction to theory and research. Reading, MA: Addison-Wesley.

Freund, A. M. (2006). Age-differential motivational consequences of optimization versus compensation focus in younger and older adults. Psychology and Aging, 21, 240-252.

Freund, A. M., \& Baltes, P. B. (2000). The orchestration of selection, optimization, and compensation: An action-theoretical conceptualisation of a theory of developmental regulation. In W. J. Perrig \& A. Grob (Eds.), Control of human behavior, mental processes and consciousness (pp. 35-58). Mahwah, NJ: Erlbaum.

Freund, A. M., \& Ebner, N. C. (2005). The aging self: Shifting from promoting gains to balancing losses. In W. Greve, K. Rothermund, \& D. Wentura (Eds.), The adaptive self: Personal continuity and intentional self-development (pp. 185-202). New York: Hogrefe.

Freund, A. M., \& Riediger, M. (2003). Successful aging. In R. M. Lerner, M. A. Easterbrooks, \& J. Mistry (Eds.), Handbook of psychology: Vol. 6. Developmental psychology (pp. 601-628). New York: Wiley.

Glanz, K., \& Gilboy, M. B. (1995). Psychosocial impact of cholesterol screening and management. In R. T. Croyle (Ed.), Psychosocial effects of screening for disease prevention and detection (pp. 39-64). London: Oxford University Press. 
Gollwitzer, P. M. (1999). Implementation intentions: Strong effects of simple plans. American Psychologist, 54, 493-503.

Heckhausen, J. (1997). Developmental regulation across adulthood: Primary and secondary control of age-related challenges. Developmental Psychology, 33, 176-187.

Heckhausen, J. (1999). Developmental regulation in adulthood: Agenormative and sociostructural constraints as adaptive challenges. New York: Cambridge University Press.

Hooker, K., \& Kaus, C. R. (1994). Health-related possible selves in young and middle adulthood. Psychology and Aging, 9, 126-133.

Kim, M. (1996). Modernizing effects on sports and physical activities among Korean adults. International Review for the Sociology of Sport, $31,155-172$

Kim, S., Moon, S., \& Popkin, B. M. (2000). The nutrition transition in South Korea. The American Journal of Clinical Nutrition, 71, 44-53.

Kim, Y. H. (2004). Korean adolescents' exercise behavior and its relationship with psychological variables based on stages of change model. Journal of Adolescent Health, 34, 523-530.

Kline, T. J. B., \& Dunn, B. (2000). Analysis of interaction terms in structural equation models: A non-technical demonstration using the deviation score approach. Canadian Journal of Behavioural Science, 32, 127-132.

Lee, M. J., Popkin, B. M., \& Kim, S. (2002). The unique aspects of the nutrition transition in South Korea: The retention of healthful elements in their traditional diet. Public Health Nutrition, 5, 197-203.

Lee, S. K., \& Sobal, J. (2003). Socio-economic, dietary, activity, nutrition and body weight transitions in South Korea. Public Health Nutrition, 6 , 665-674.

Leventhal, E. A., \& Prochaska, T. R. (1986). Age, symptom interpretation, and health behavior. Journal of the American Geriatrics Society, 34, 185-191.

Leventhal, H., Singer, R., \& Jones, S. (1965). Effects of fear and specificity of recommendation upon attitudes and behavior. Journal of Personality and Social Psychology, 2, 20-29.

Lippke, S., Ziegelmann, J. P., \& Schwarzer, R. (2004). Behavioral intentions and action plans promote physical exercise: A longitudinal study with orthopedic rehabilitation patients. Journal of Sport \& Exercise Psychology, 26, 470-483.

Little, T. D., Cunningham, W. C., Shahar, G., \& Widaman, K. F. (2002). To parcel or not to parcel: Exploring the question, weighing the merits. Structural Equation Modeling, 9, 151-173.

Lockwood, P., Chasteen, A. L., \& Wong, C. (2005). Age and regulatory focus determine preferences for health-related role models. Psychology and Aging, 20, 376-389.

Luszczynska, A., \& Schwarzer, R. (2003). Planning and self-efficacy in the adoption and maintenance of breast self-examination: A longitudinal study on self-regulatory cognitions. Psychology \& Health, 18, 93-108.

Luszczynska, A., \& Sutton, S. (2006). Physical activity after cardiac rehabilitation: Evidence that different types of self-efficacy are important in maintainers and relapsers. Rehabilitation Psychology, 51, 314321.

MacCallum, R. C., Widaman, K. F., Zhang, S., \& Hong, S. (1999). Sample size in factor analysis. Psychological Methods, 4, 84-99.

Marlatt, G. A., Baer, J. S., \& Quigley, L. A. (1995). Self-efficacy and addictive behavior. In A. Bandura (Ed.), Self-efficacy in changing societies (pp. 289-315). New York: Cambridge University Press.

Miller, D. J., Freedson, P. S., \& Kline, G. M. (1994). Comparison of activity levels using the Caltrac accelerometer and five questionnaires. Medicine and Science in Sports and Exercise, 26, 376-382.

Milne, S., Orbell, S., \& Sheeran, P. (2002). Combining motivational and volitional interventions to promote exercise participation: Protection motivation theory and implementation intentions. British Journal of Health Psychology, 7, 163-184.

Netz, Y., Wu, M.-J., Becker, B. J., \& Tenenbaum, G. (2005). Physical activity and psychological well-being in advanced age: A meta-analysis of interventions studies. Psychology and Aging, 20, 272-284.

Norman, P., \& Conner, M. (2005). The theory of planned behavior and exercise: Evidence for the mediating and moderating roles of planning on intention-behavior relationships. Journal of Sport \& Exercise Psychology, 27, 488-504.

Nurmi, J. E. (1992). Age differences in adult life goals, concerns, and their temporal extension: A life course approach to future-oriented motivation. International Journal of Behavioral Development, 15, 487-508.

Organisation for Economic Co-operation and Development. (2005). Thematic review on adult development - Korea: Country note. Retrieved June 14, 2006, from http://www.oecd.org/dataoecd/6/14/34936685.pdf

Penny, G. N., Bennett, P., \& Herbert, M. (1994). Health psychology: A lifespan perspective. Chur, Switzerland: Harwood Academic Publishers.

Perloff, L. S., \& Fetzer, B. K. (1986). Self-other judgments and perceived vulnerability to victimization. Journal of Applied and Social Psychology, 50, 502-510.

Prochaska, J. O., Johnson, S., \& Lee, P. (1998). The transtheoretical model of behavior change. In S. A. Shumaker, E. B. Schron, J. K. Ockene, \& W. L. McBee (Eds.), The handbook of health behavior change (pp. 59-84). New York: Springer.

Renner, B., Knoll, N., \& Schwarzer, R. (2000). Age and body weight make a difference in optimistic health beliefs and nutrition behaviors. International Journal of Behavioral Medicine, 7, 143-159.

Renner, B., \& Schwarzer, R. (2003). Social-cognitive factors in health behavior change. In J. Suls \& K. Wallston (Eds.), Social psychological foundations of health and illness (pp. 169-196). Oxford, England: Blackwell.

Renner, B., \& Schwarzer, R. (2005). The motivation to eat a healthy diet: How intenders and nonintenders differ in terms of risk perception, outcome expectancies, self-efficacy, and nutrition behavior. Polish Psychological Bulletin, 36, 7-15.

Riediger, M., \& Freund, A. M. (2006). Focusing and restricting: Two aspects of motivational selectivity in adulthood. Psychology and Aging, $21,173-185$.

Rodgers, W. M., Hall, C. R., Blanchard, C. M., McAuley, E., \& Munroe, K. J. (2002). Task and scheduling self-efficacy as predictors of exercise behavior. Psychology \& Health, 27, 405-416.

Rodgers, W. M., \& Sullivan, M. J. L. (2001). Task, coping and scheduling self-efficacy in relation to frequency of physical activity. Journal of Applied Social Psychology, 31, 741-753.

Rybash, J. W., Roodin, P. A., \& Hoyer, W. J. (1995). Adult development and aging. Madison, WI: Brown \& Benchmark.

Schafer, J. L., \& Graham, J. W. (2002). Missing data: Our view of the state of the art. Psychological Methods, 7, 147-177.

Scholz, U., Sniehotta, F. F., Burkert, S., \& Schwarzer, R. (in press). Increasing physical exercise levels: Age-specific benefits of planning. Journal of Aging and Health.

Scholz, U., Sniehotta, F. F., \& Schwarzer, R. (2005). Predicting physical exercise in cardiac rehabilitation: The role of phase-specific self-efficacy beliefs. Journal of Sport \& Exercise Psychology, 27, 135-151.

Schwarzer, R. (1992). Self-efficacy in the adoption and maintenance of health behaviors: Theoretical approaches and a new model. In R. Schwarzer (Ed.), Self-efficacy: Thought control of action (pp. 217-243). Washington, DC: Hemisphere.

Schwarzer, R., \& Renner, B. (2000). Social-cognitive predictors of health behavior: Action self-efficacy and coping self-efficacy. Health Psychology, 19, 487-495.

Schwarzer, R., Schüz, B., Ziegelmann, J. P., Lippke, S., Luszczynska, A., \& Scholz, U. (2007). Adoption and maintenance of four health behaviors: Theory-guided longitudinal studies on dental flossing, seat belt use, dietary behavior, and physical activity. Annals of Behavioral Medicine, 33, 156-166. 
Sheeran, P. (2002). Intention-behavior relations: A conceptual and empirical review. European Review of Social Psychology, 12, 1-36.

Shin, Y. H., Yung, S. K., Pender, N. J., \& Jang, H. J. (2005). Test of the health promotion models as a causal model of commitment to a plan for exercise among Korean adults with chronic disease. Research in Nursing and Health, 28, 117-125.

Sniehotta, F. F., Scholz, U., \& Schwarzer, R. (2005). Bridging the intention-behaviour gap: Planning, self-efficacy, and action control in the adoption and maintenance of physical exercise. Psychology \& Health, 20, 143-160.

Sniehotta, F. F., Scholz, U., \& Schwarzer, R. (2006). Action plans and coping plans for physical exercise: A longitudinal intervention study in cardiac rehabilitation. British Journal of Health Psychology, 11, 23-37.

Spiro, A. (2001). Health in midlife: Toward a life-span view. In M. E. Lachman (Ed.), Handbook of midlife development (pp. 156-187). New York: Wiley \& Sons.

Staudinger, U. M., Freund, A., Linden, M., \& Maas, I. (1999). Self, personality, and life management: Psychological resilience and vulnerability. In P. B. Baltes \& K. U. Mayer (Eds.), The Berlin Aging Study: Aging from 70 to 100 (pp. 302-326). New York: Cambridge University Press.

Staudinger, U. M., \& Schindler, I. (2005). Personal life investment: A window on adaptation across the life span. Manuscript submitted for publication
Tabachnick, B. G., \& Fidell, L. S. (2001). Using multivariate statistics (4th ed.) Boston: Allyn and Bacon.

U.S. Department of Health and Human Services. (1999). Promoting physical activity: A guide for community action. Champaign, IL: Human Kinetics.

Wareham, N. J., Jakes, R. W., Rennie, K. L., Mitchell, J., Hennings, S., \& Day, N. E. (2002). Validity and repeatability of the EPIC-Norfolk Physical Activity Questionnaire. International Journal of Epidemiology, $31,168-174$

Weinstein, N. D. (1993). Testing four competing theories of healthprotective behavior. Health Psychology, 12, 324-333.

Weinstein, N. D. (2003). Exploring the links between risk perceptions and preventive health behavior. In J. Suls \& K. Wallston (Eds.), Social psychological foundations of health and illness (pp. 22-53). Oxford, England: Blackwell.

World Health Organization. (2003). Diet, nutrition, and the prevention of chronic diseases (World Health Organization Technical Reports Series 916). Geneva, Switzerland: Author.

Ziegelmann, J. P., Lippke, S., \& Schwarzer, R. (2006). Adoption and maintenance of physical activity: Planning interventions in young, middle-aged, and older adults. Psychology \& Health, 21, 145-163.

Received January 31, 2006 Revision received November 29, 2006 Accepted March 16, 2007

\section{Low Publication Prices for APA Members and Affiliates}

Keeping you up-to-date. All APA Fellows, Members, Associates, and Student Affiliates receive-as part of their annual dues-subscriptions to the American Psychologist and APA Monitor. High School Teacher and International Affiliates receive subscriptions to the APA Monitor, and they may subscribe to the American Psychologist at a significantly reduced rate. In addition, all Members and Student Affiliates are eligible for savings of up to $60 \%$ (plus a journal credit) on all other APA journals, as well as significant discounts on subscriptions from cooperating societies and publishers (e.g., the American Association for Counseling and Development, Academic Press, and Human Sciences Press).

Essential resources. APA members and affiliates receive special rates for purchases of APA books, including the Publication Manual of the American Psychological Association, and on dozens of new topical books each year.

Other benefits of membership. Membership in APA also provides eligibility for competitive insurance plans, continuing education programs, reduced APA convention fees, and specialty divisions.

More information. Write to American Psychological Association, Membership Services, 750 First Street, NE, Washington, DC 20002-4242. 